\title{
Code-switching in university classroom interaction: A case study of the University of Dar es Salaam
}

\author{
Nikuigize Erick Shartiely \\ Department of Foreign Languages and Linguistics, University of Dar es Salaam, Tanzania \\ E-mail: etiely@yahoo.com
}

\begin{abstract}
Code-switching, a common linguistic practice among multilingual speakers, occurs when a speaker alternates between two or more language varieties in a single conversation. This phenomenon manifests itself in diverse ways and to achieve different goals. It may occur within or between sentences; it may signify social aspects such as identity or solidarity among people who share values; and, as this paper demonstrates, it may serve instructional purposes. This paper examines the alternating use of English and Swahili in lectures at the University of Dar es Salaam in the context of Tanzania's language-in-education policy, which makes English the sole language of teaching and learning in higher education. The data comprise eight recorded lectures and interviews with the lecturers teaching first-year students in the departments of Political Science and Public Administration (PSPA) and Sociology and Social Anthropology (SSA). The study was premised on the assumption that lecturers are likely to make marked language choices consciously or unconsciously with firstyear students because they are new to the university's English spoken register. The primary objective of this particular paper is to identify, describe, document and analyse the types of code-switching that lecturers used during lectures. A discourse analysis (DA) approach facilitated the identification and analysis of the lecturers' code-switching. The findings indicate that lecturers used inter- and intrasentential code-switching to engage with students, to translate concepts, to explain, to manage students' behaviour, and to advise or encourage students. This paper broadens our understanding of individual and societal multilingualism and how lecturers manage it in the context of higher education in Tanzania. It highlights practical issues of English language usage in Tanzanian higher education as an instance of the use of English as an academic lingua franca in contexts where a local language dominates practically all other spheres of the speakers' lives.
\end{abstract}

Keywords: code-switching, lectures, language-in-education policy, higher education, multilingualism

\section{Introduction}

Code-switching, the practice of moving back and forth between two languages or between two dialects or registers of the same language, is a common practice among multilingual speakers from all walks of life. Not surprisingly, it has drawn the attention of scholars who have approached it 
from a range of perspectives, including formal or structural linguistics (cf. Poplack 2001), psycholinguistics (cf. Taha 2009) and sociolinguistics (Gumperz and Bloom 2000; Myers-Scotton 1993, 1997). Others have approached it from educational (cf. Lin 2008, 2013) and neuro-linguistic perspectives (cf. Bialystok 2001, 2009; Bialystok, Craik, Green and Gollan 2009; Westly 2011). In the past, code-switching has been viewed negatively, even by academics. For example, Grosjean (2008:20) reports that some researchers have tended to appraise bilinguals' language skills based on monolingual standards. Code-switching has thus been regarded as "contaminating", and has been dismissed as 'bad practice' constituting ungrammatical language usage characteristic of semilingual speakers without complete control of either of their languages (Grosjean 1982:147). Notwithstanding the social stigma attached to code-switching, particularly in restrictive formal environments, code-switching in bilingual societies is increasingly becoming valued as a useful communicative strategy in facilitating the achievement of interactional goals in different domains (cf. Shartiely 2013; Shin 2010; Shin and Milroy 2000). In fact, code-switching manifests itself in diverse ways in order to meet particular goals, such as signifying identity or achieving solidarity among people with shared values (cf. Cook 2003; Walker 2011), or for instructional purposes when learners have inadequate mastery of the language of instruction (cf. Shartiely 2013; Shin 2010; Taha 2009; Uys 2010; Zabrodskaja 2009).

Language and language-in-education policies in Tanzania have been subject to many contradictions in their ratification and implementation. In the language policy of 1995, Kiswahili was designated as the language of instruction (LoI) from pre-primary to the end of primary education, while English would continue to be used as LoI in secondary schools through to tertiary level. Some scholars (cf. Swilla 2009) have called the language-in-education policy in Tanzania contradictory. Swilla (2009:2) identifies three ideological periods in relation to language-in-education policy in Tanzania. The first period is the first five years after independence (1961-1966), during which Tanzania maintained the capitalist form of government that it had inherited from the previous regime. The second is the period between 1967 and the early 1980s, during which Tanzania adopted socialism as a form of government. The third is the period from the late 1980s up to the present, during which Tanzania returned to capitalism. All these ideological changes have had a significant impact on the language-ineducation policy in Tanzania, as explicated below.

During the first period (1961-1966), the government made significant changes to the former colonial system, including abolishing school fees for secondary school education with the aim of allowing wider access for African learners. However, Swilla (2009:3) notes, the government maintained the colonial curriculum and LoI policy, whereby Kiswahili continued to be used as LoI in the first years of primary education and English continued to be used as LoI from the sixth year of primary education through secondary school up to post-secondary school level.

During the second period (1967-mid 1980s), the government nationalised all the major means of production in the country. The "Education for Self-Reliance" policy was adopted, and the government promised free provision of social services, including education. At this stage, Kiswahili was adopted as LoI for the entirety of primary school education. A small number of English-medium primary schools were maintained to cater for children of expatriates. However, these schools were not allowed to enroll Tanzanian learners (Swilla 2009:3).

During the third period, socialism was gradually abandoned; though it is still officially included in the Tanzanian constitution. This abandonment was mainly due to economic pressures that the government experienced in the late 1970s due to rising oil prices, the falling prices of raw 
materials on the world market, drought, famine, and the war against Idi Amin of Uganda. This necessitated a move from a state-controlled to a free market economy that entailed the liberalisation and privatisation of major means of production and state-owned enterprises. Eventually, privatisation was reintroduced into the education system by legalising the use of English in private primary schools in 1992, and finally by extending the right to use English as LoI in 1995 by means of Education Amendment Act No. 10 (Swilla 2009:4).

In Tanzania there have been several policy statements, sometimes contradicting one another, with regard to the status of both English and Swahili in academic settings. For instance, The Ministry of Education and Vocational Training policy (2014:38) contains both a statement supporting the continued use of English as LoI at the secondary and tertiary education levels, and one supporting the introduction of Swahili as LoI at all levels of education. The statements are as follows:

3.2.5. Lugha ya Taifa ya Kiswahili itatumika kufundishia na kujifunzia katika ngazi zote za elimu na mafunzo na Serikali itaweka utaratibu wa kuwezesha matumizi ya lugha hii kuwa endelevu na yenye ufanisi katika kuwapatia walengwa elimu na mafunzo yenye tija kitaifa na kimataifa.

3.2.6. Serikali itaendelea na utaratibu wa kuimarisha matumizi ya lugha ya Kiingereza
katika kufundishia na kujifunzia, katika ngazi zote za elimu na mafunzo.
Sera ya Elimu na Mafunzo (Ministry of Education and Vocational Training policy)

(2014: 38)

\section{Translation (author's own):}

3.2.5. Swahili National language will be used for teaching and learning at all levels of education and training and the government will put in place mechanisms to facilitate the use of this language to be sustainable and effective in providing learners with productive education and training nationally and internationally.

3.2.6. The government will continue with the mechanism to strengthen the use of English in teaching and learning, at all levels of education and training.

Before the Tanzanian government's recent decision, Swahili had been the LoI for public primary schools and English, as hinted above, served that purpose at the secondary and tertiary education levels. Under this problematic arrangement, the majority of Tanzanian students found themselves in the deep end of the English-language pool in secondary school: they had to learn how to swim by developing language competency, or drown if they failed to reach the required proficiency level.

Generally, code-switching as an instance of bilingual practice entails bilinguals' ability to choose and use language in a variety of ways. For example, they are said to exhibit more creativity (cf. Bialystok 2011; Hamers and Blanc 2000), to be able to reflect on and manipulate language more adeptly (Bialystok 2001), and to be more context-sensitive (Cenoz, Hufeisen and Jessner 2003) than their monolingual counterparts. Nevertheless, the predominant view that code-switching is a language handicap remains widespread at the University of Dar es Salaam, the country's oldest university. Indeed, authorities at the university have occasionally posted notices to deter lecturers and students from mixing Swahili and English (thus producing what has been dubbed 
"Kiswanglish") during classroom interaction to abide by the official language policy. ${ }^{1}$ This is somewhat paradoxical, as it ignores the fact that most of them are multilingual in the languages of Tanzania; thus, they cannot avoid resorting to one or more language when they have to do so. Because of the social stigma attached to code-switching and stringent rules aimed at curbing the practice at any cost, little attention has been paid to how code-switching facilitates the delivery of content in academic settings; particularly in contexts where the official LoI on the whole makes both lecturers and students uncomfortable. And yet the reality on the ground is that code-switching is a fait accompli. Stakeholders have thus been denied knowledge on how lecturers improvise during classroom interaction with the aim of achieving a smooth flow of content and imparting of knowledge. What remains indisputable is the fact that University of Dar es Salaam lecturers tend to defy the directive forbidding code-switching, as well as the policy that gives rise to this linguistic dilemma in the classroom situation, for practical reasons and convenience. This paper delineates how and why lecturers of the University of Dar es Salaam code-switch during classroom interaction regardless of the censure and rebuke they receive from institutional authorities, including the university's Quality Assurance Bureau.

\section{Defining the terms "code-switching" and "classroom code-switching"}

There are various definitions of the term "code-switching". Swann and Sinka (2007:242) observe that the definitions vary so greatly that the term can also encompass switching between dialects (cf. Gumperz's (1982) concept of 'situational code-switching'). Lin (2013:195) describes 'classroom code-switching' as the alternating use of more than one linguistic code in the classroom by any of the classroom participants. In this paper, I consider code-switching (be it in the classroom or elsewhere) in accordance with Poplack (2001:262) as the practice of bilingual or multilingual speakers using two or more languages in discourse, either mixing them by introducing words or shorter phrases, or switching between the two languages with longer units of each. Many bilingual teachers use two languages to teach academic content, switching between the languages spontaneously or intentionally (cf. Taha 2009:336). They may also code-switch to facilitate comprehension and to create meaningful involvement (Zabrodskaja 2007:124).

Traditionally, two types of code-switching are identified within sociolinguistics, namely situational and metaphorical code-switching (Gumperz and Bloom 2000:126). According to Gumperz and Bloom (2000: 126), situational code-switching stems from a change in situation, such as switching from a more prestigious language to a less prestigious one; whereas metaphoric codeswitching arises out of the need to achieve a special communicative effect, such as the expression of identity and/or solidarity. From a structural perspective, there are two main types of code-switching; namely "inter-sentential" code-switching, which occurs between sentences, and "intra-sentential" code-switching, which occurs within the same sentence (cf. Poplack 2001). In this paper, the codeswitching under study is language alternation between English and Swahili by native Swahilispeaking lecturers at the University of Dar es Salaam. This paper is based on the findings of a study that focused primarily on the various functions of code-switching in bilingual or multilingual classrooms (see Shartiely 2013).

The study found that both situational and metaphoric code-switching take place at the University of Dar es Salaam. As stated above, situational code-switching stems from a change in situation, whereas metaphoric code-switching arises out of the need to achieve a special communicative effect (Gumperz

\footnotetext{
${ }^{1}$ This is based on my personal experience as member of teaching staff of the University of Dar es Salaam.
} 
and Bloom 2000:126). For example, an academic administrator at the University of Dar es Salaam can switch from speaking English, the academically unmarked code, to Swahili, the marked code. Such situational code-switching is motivated by the fact that, like any other academic institution, the university community is made up of both academic and non-academic members of staff. Among nonacademic staff, the use of English is not mandatory, and many probably do not have an advanced command of the language. Fishman (1967:36) refers to this kind of code-switching as operating at a macro level, where two languages, each with distinct functions in specific situations, are used in alternation. In other words, language choice depends on the topic, interlocutors and setting. Codeswitching at a micro level, on the other hand, amounts to what Gumperz (1982:61) and Gumperz and Bloom (2000:126) call "conversational code-switching". This type of code-switching is characteristic of verbal interactions among speakers of more than one language. It marks aspects of discourse such as quotations, addressee specification, interjections, reiteration, message qualification and personalisation, translation, elaboration and explanation of materials presented in English (Gulzar 2010:37; Gumperz 1982:59; Taha 2009:342). Unlike macro-level code-switching, which is between two distinct languages that are alternately and systematically used in different situations by designated participants, micro-level code-switching occurs within a single speech event, often in the spoken contribution of a single participant. It occurs between sentences (inter-sentential), within sentences (intra-sentential), and even within words.

At the University of Dar es Salaam, such conversational code-switching (metaphoric code-switching) occurs during classroom interaction, specifically during lectures. Thus, similarly to what happens in communication between the university administration and the university's academic community, classroom interaction often exhibits code-switching between English and Swahili. Such codeswitching serves a specific function geared towards achieving a certain communicative effect.

On the whole, code-switching has a number of similar functions across different bilingual and multilingual situations. Gumperz (1982:59) recognises code-switching as a discourse strategy for bilinguals. Myers-Scotton (1993:476) observes that code-switching occurs at any linguistic level in the negotiation of interpersonal relationships and signalling of social group memberships. She further identifies two major reasons that prompt speakers to resort to code-switching. These are firstly to fill the gap of a missing item in the expected language and secondly to express the speaker's creativity in the process of negotiating a public face. In this regard, linguistic studies of the regularity of codeswitching among bilingual teachers have been conducted at both the lower levels of education (cf. Mwinsheikhe 2009; Olmo-Castillo 2014; Rubagumya 2008; Shin 2010; Uys 2010; van der Walt and Klapwijk 2015) and higher levels of education (cf. Li 2008; Mashiyi 2014; Shartiely 2013; Taha 2009; Zabrodskaja 2007, 2008, 2009), with similar results.

More recently, new concepts such as 'code-meshing' (cf. Canagarajah 2011a; Young, Barrett, YoungRiviera and Lovejoy 2011) and 'translanguaging' (cf. García 2009; Creese and Blackledge 2010) have been introduced, specifically under the influence of postmodern sociolinguistics. According to Lin (2013:196), these concepts "seek to take away the markedness of the linguistic phenomenon traditionally called "code-switching" and conceptualise it as a social practice that is part and parcel of everyday social life". According to García (2009:140), translanguaging refers to bilinguals' accessing of different linguistic features or various modes of what are described as autonomous languages to maximise communicative potential. Figuratively, Canagarajah (2011a:2) relates translanguaging to the ability of multilingual speakers to shift between the different languages that make up their repertoire, thereby treating it as an integrated system. Translanguaging performs numerous important roles in the teaching and learning process, such as helping students develop a deeper 
understanding of the subject content, and allowing for the provision of more rigorous content, the affirmation of multiple identities, and the development of relevant language for performing specific academic tasks (Lenis 2015:71). Young et al. (2013:2) define "code-meshing" as the act of combining two or more language systems and/or communication modes to write and speak effectively within the various domains of society.

Although these three concepts all involve the alternation between multiple languages in discourse, they differ in their theoretical orientations. For example, in code-meshing, multilinguals are seen as merging their varied linguistic resources with the dominant language to construct a hybrid text (be it written or spoken). Translanguaging moves beyond the constructed hybrid text to accommodate other semiotic resources such as colour, images and symbols (Canagarajah 2013:40-41). Although language-in-education policies in postcolonial societies discourage the use of the first language alongside the second language, translanguaging in educational practices has actually proved to be an important pedagogical resource in the teaching and learning process (cf. Blackledge and Creese 2014; Hibbert and Van der Walt 2014). Nevertheless, as Blackledge and Creese (2014:206) remark, the major challenge to translanguaging is the question of how to harness existing multilingual practices for pedagogical purposes

This article, although acknowledging the work done on translanguaging within educational contexts, takes code-switching as its theoretical point of departure. This is done because the article confines itself to the classroom practice of alternating between two languages (Swahili and English) in a context where policy endorses English as the medium of communication. Code-switching in the context of this article is one-sided, as it involves teachers only and gives learners no opportunity to participate in the process. Furthermore, lecturers do perceive the switching between two languages as transgressing boundaries. For them, then, language is viewed as a bounded system. Given the aims of this article and the particular context in which it was conducted, the concepts of 'translanguaging' and 'code-meshing' were not ideally suited to achieve the study's objective, which was to investigate how lecturers of the University of Dar es Salaam use code-switching as a teaching strategy.

Numerous studies on code-switching in multilingual classrooms at the tertiary level in different parts of the world have been done. These include studies on code-switching between English and Swahili at the University of Dar es Salaam (Shartiely 2013), on code-switching between Arabic and English at the University of Khartoum in Sudan (Taha 2009), on code-switching between Cantonese and English at the Hong Kong Institute of Education (Li 2008), and on code-switching between Estonian and Russian at Tallinn University (Zabrodskaja 2007, 2008, 2009). Other studies have been conducted on code-switching between Xhosa and English at the University of the Western Cape (Banda 2007), and on code-switching between Rwandese and English at the National University of Rwanda (Kagwesage 2013). These studies illustrate that bilingual lecturers use two languages to teach by switching between languages spontaneously or intentionally. Zabrodskaja (2007:127) has established that lecturers decide when to code-switch between Estonian and Russian to facilitate comprehension and foster meaningful classroom interaction. Taha (2009:336) reports that lecturers code-switch between English and Arabic as both a pedagogical tool and strategy to initiate effective classroom interaction and topic change and to cultivate solidarity with students. Similarly, Li (2008:84) found that lecturers code-switch between Cantonese and English to achieve communicative goals, to clarify difficult concepts, to expand and/or consolidate students' bilingual lexicon, and to reduce social distance from students to assist them psychologically. Additionally, Banda (2007) asserts that tutors and lecturers who shared a Xhosa/English repertoire with students fostered the use of Xhosa in 
informal classroom working sessions, despite not using Xhosa during tutorials or during consultations in their office. Kagwesage (2013) found that, although other spoken languages are not officially recognised as media of instruction in higher education, they play a mediating role in content learning through responsible code-switching and translanguaging. Although, contrary to the Sudanese and Estonian contexts, the language policy at the University of Dar es Salaam does not officially condone such practices, the reality on the ground attests to similar practices at the institution (Shartiely 2013).

\section{Methodology}

Purposive sampling was applied in this study to draw participants from the departments of Political Science and Public Administration (PSPA) and Sociology and Social Anthropology (SSA). When this study was conducted, these two departments were among the largest in terms of the number of registered students in the then-College of Arts and Social Sciences (CASS), which has now been reconstituted into two colleges: the College of Social Sciences (CoSS), under which both the PSPA and SSA departments fall, and the College of Humanities (CoHu). Moreover, these courses are mostly taught through lectures, due to the large classes. This teaching method was appropriate for the cases under study, which involved lectures and lecturers (not seminars and students). From each department, four lecturers who taught first-year classes participated in the study. This also applied to the courses in which recordings were done, namely first-year course lectures, thus ensuring the coverage of all the courses taught at university-entrance level. Coincidentally, senior and junior faculty were paired to teach the classes. Thus, it could be investigated how the lecturers used codeswitching according to their status. However, the findings indicated no significant differences between junior and senior faculty's use of code-switching.

Both observation and interviews were used to collect broad-based data on the use of code-switching practices in the classroom. The study did not include students as it sought to investigate how lecturers accommodate students who often have little background in English, the university's spoken discourse, because of their pre-university ill-preparedness for rigorous advanced learning resulting from the flawed national language policy. The study thus collected and analysed data that provided in-depth information on code-switching practices from the lecturers' perspectives.

Data collection on the types of code-switching that lecturers use when lecturing and on the lecturers' own reflections on the use of code-switching considering the variety of linguistic resources available to them and students combined the use of audio-visual recording and semi-structured interviews. The audio-visual recording involved eight 55-minute single-session lectures. The lectures were transcribed and subsequently organised according to two major categories of the instances of code-switching that transpired, namely intra-sentential and inter-sentential code-switching. The analysis of the transcripts on how regularly the lecturers used code-switching was followed by semi-structured interviews with the respective lecturers exploring their reflections on code-switching practices. The data were grouped into four themes. The first theme covered general information about the lecturer, including their educational background and teaching experience, whether they had trained as teachers, and whether they had undertaken any teaching methodology courses in their careers. The second theme covered the language of instruction that was used during their studies. The third theme related to their opinion regarding the observations made by different stakeholders about the low level of English proficiency at the University of Dar es Salaam, how this situation influenced the way they taught, and how they handled a situation where they introduced a topic and discovered that students could not comprehend it. The fourth theme explored why they had used the discourse strategies that had been observed during the lecture sessions, and whether they used different 
strategies in other classes. The last theme examined their views regarding the difficulty that students face in learning in English, and whether they would recommend the use of Kiswahili as medium of instruction at university level.

\section{Results and discussion}

The study found that two major types of code-switching take place at the University of Dar es Salaam: situational and metaphoric code-switching. One hundred instances of code-switching were found. Intra-sentential code-switching occurred 70 times $(70 \%)$, whereas inter-sentential codeswitching occurred 30 times (30\%) (see Table 1). This means that intra-sentential code-switching occurred on average after every 6 minutes in the 400 minutes of lecture time, whereas inter-sentential code-switching occurred after every 13.3 minutes, as Table 1 illustrates:

Table 1: Types and frequencies (in percentage) of code-switching

\begin{tabular}{|l|l|l|l|l|l|l|l|l|l|}
\hline Type & L1 & L2 & L3 & L4 & L5 & L6 & L7 & L8 & Total \\
\hline Inter-sentential & 08 & 01 & 01 & & - & 15 & 04 & 01 & 30 \\
\hline Intra-sentential & 17 & 04 & 04 & 01 & 20 & 21 & 02 & 01 & 70 \\
\hline Total & 25 & 05 & 05 & 20 & 20 & 36 & 06 & 02 & \\
\hline Grand total & & & & & & & & & 100 \\
\hline
\end{tabular}

\subsection{Intra-sentential code-switching}

The study found that lecturers used more intra-sentential than inter-sentential code-switching. Examples are provided in the following excerpts. Specifically, excerpt (1) shows how lecturers used intra-sentential code-switching for clarification and advising purposes; excerpt (2) illustrates how lecturers used code-switching to clarify a point; and excerpt (3) illustrates how they used it for exemplification purposes. Gulzar (2010:37) found that in such instances code-switching does not only assist the lecturer to clarify, advise and give directives, but also to simplify expressions.

1 When you see the country is peaceful ... there is somebody who must have

2 done something. Na ndiyo maana ['and that is why'] as a new

3 generation ... you should also aim at ... trying to pay mchango wako

4 ['your contribution'] ...

In excerpt (1), the lecturer continues speaking about how the immense contributions of Africans who struggled for the independence of Africa made countries such as Tanzania peaceful (line 1). She codeswitches to Swahili to clarify what the new generation should do to emulate their nation's founders (line 2). She finally advises students, as a new generation, on what they should try to do "... trying to pay mchango wako" (line 3). 
1 So... this particular relationship between these two sets of individuals is

2 mediated by inanimate thing called gari ['car']. So through gari

3 this particular power of these particular individuals is mediated.

In excerpt (2), the lecturer explains how the owner of a commuter bus relates to the driver and the conductor of the bus through the bus itself. In explaining how that relationship exists, the lecturer uses a Swahili word for car ("through the gari ["car']") to clarify how in materialist contexts power relations can be mediated by inanimate things.

1 ...Now, this one [...] depends upon your office, upon your office, not the

2 office holder, he may be the shortest, but he is the boss; the Chief

3 Executive Officer; shortest, shortest man like a mbilikimo ['dwarf'] but

4 [he or she] is the boss because of the position he or she holds.

In excerpt (3), the lecturer differentiates between types of authority and clarifies the differences between them (line 1-2). Then he uses a simile - “... shortest man like a mbilikimo ['dwarf']" - to emphasise the point that an individual's physical characteristics do not count when it comes to those with authority. This usage creates not only humour but also a sense of belonging, because it uses the term mbilikimo, which students are familiar with. In fact, the term is often used as a derogatory term when remarking on an individual's socially undesirable height.

\subsection{Inter-sentential code-switching}

The following excerpts illustrate how lecturers use inter-sentential code-switching to achieve different communicative goals, such as elaborating on a process (excerpt 4) and checking for understanding (excerpt 5). Uys (2010:33ff.) found that lecturers may code-switch to explain a point, confirm understanding, encourage students' participation and give general instructions.

1 ...A process through which they acquire a culture, which is viewed as consistent,

2 coherent, definite and so, in the process of growing up people acquire a culture.

3 Wanakunywa ile... ['they drink that culture'] as a process, as a passive process

In excerpt (4), the lecturer explains how people acquire culture through a thorough process. The lecturer likens this process to drinking ("Wanakunywa ile ..." ['they drink that culture'] (line 3)). This code-switching practice helps the lecturer simplify his explanation using the simple but familiar process of drinking. The usage also helps the lecturer to create humour, thus capturing the students' attention and generating interest.

1 ... rather than the continuing relations with the metropolitan countries.

2 Topic number two ... hiyo mmeichukua? ['Have you understood that?'] Should I

3 repeat?

In excerpt (5), the lecturer reads a series of seminar questions to the students, which they must prepare for the next seminar session. Whenever she reads a question, students grumble to indicate that they have not written down the question properly. After re-reading the seminar questions several times, the lecturer resorts to the use of Swahili to check whether the students have written down the question properly (“... hiyo mmeichukua?” ['Have you understood that?']). 


$$
\begin{aligned}
& 1 \text { kama nilivyokwisha kusema hapo awali ['as I had said earlier'] politics does not } \\
& 2 \text { only involve ...involve the identification as well as the specification of the } \\
& 3 \text { three institutions of the state. Kama nilivyosema ['as I had put it'], the Legislature, } \\
& 4 \text { the Judiciary and the Executive. }
\end{aligned}
$$

Excerpt (6) illustrates how code-switching facilitates cohesion and topic development. In this instance, the lecturer switches to Swahili to refer to a point mentioned earlier (line 1), and repeats this switch in the conclusion (line 3). This strategy allows the lecturer to place emphasis on the three institutions of the state (lines 3-4). The lecturer uses code-switching to prompt students to recall the point made earlier, thus signalling topic connectivity and continuity. Taha (2008:342) reports a similar trend at the University of Khartoum, where lecturers code-switch from English to Arabic during classroom interaction to repeat and elaborate on materials presented in English.

$$
\begin{aligned}
& 1 \text { They had to - in Swahili we say kuvumilia [to tolerate]. Africans recognised } \\
& 2 \text { that the governments of Europe and America, especially Europe, had come to } \\
& 3 \text { Africa ... Because, as I told you, this man who is called Leopold said that 'we came } \\
& 4 \text { to perpetuate ourselves yaanitumekuja kukaa siyo kuvisit ['that is, we came to } \\
& 5
\end{aligned}
$$

Excerpt (7) shows how a lecturer uses code-switching for translational emphasis and cohesion purposes. In line (1), the lecturer translates a Swahili concept kuvumilia 'to tolerate' that expresses her feelings regarding the hardship that the forefathers of the local community endured under the yoke of colonialism. Then she adds an emotional touch by translating an English quotation given more than 30 minutes earlier in the same lecture into Swahili (line 4) to refocus the topic. This use underscores the complex nature of code-switching in a multilingual situation, and is in line with Taha's (2008:342) observation that teacher code-switching facilitates translations, elaborations and explanations of materials presented in English.

$$
\begin{aligned}
& 1 \text { When we discuss the relationship between a state and what we call the civil society... } \\
& 2 \text { are we proceeding accordingly? ... hata dakika ishirini hazijafika watu wanaanza... } \\
& 3 \text { [Even before twenty minutes have elapsed people start ... . mjitahidi, } \\
& 4 \text { tujitahidi, tujitahidi, ['Keep on trying, let's keep on trying, let's keep on trying'] } \\
& 5 \\
& \text { Nafikiri inaeleweka vizuri si ndiyo? [...' I think it is well understood, isn't it?'] } \\
& 6 \text {... I was saying that politics ... }
\end{aligned}
$$

In excerpt (8), a lecturer uses code-switching to manage the behaviour of the students when they seem to lose attention only 20 minutes into the lecture (line 2). The lecturer also uses code-switching to advise students to stay focused and keep up with the lecture (lines 2-3), while also checking whether he had control of the class by using confirmation questions (lines $2,4,5$ ). This is in line with the findings of Shin (2010:111), who notes that teacher code-switching can reinforce directives, mitigate classroom disorder and emphasise the teacher's position as an authority

\subsection{Lecturers' motivation for code-switching in lectures}

When asked to elaborate on their code-switching between English and Swahili, all eight lecturers reported that they resort to Swahili upon realising that students do not quite follow or understand the subject matter (excerpt 9). One lecturer even admitted that the classroom situation compels him to code-switch, despite the university regulation outlawing the practice. 
Of course, I use Swahili when I want students to understand me more. I decide to use a story or explain a concept in Swahili because I know my students. When I use Swahili they start wondering ... was this the concept? ... It is as, I said, when I repeat [it] twice and ask them if they understand [it] and they say no! I use Swahili with simple examples in Swahili. Then I am convinced that they have understood. I know that may be they have not written down the concept, but at least they have understood it.

In excerpt (9), the lecturer argues that she code-switches from English to Swahili during lectures to facilitate understanding by providing translations and examples, by simplifying the content, and by mitigating spelling errors.

(10) I normally speak in Swahili. Under the university requirements, we are supposed to lecture in English and not in Swahili. But I do violate it [this rule] especially when I realise that students cannot understand concepts or theories in English... I decide to use Swahili hoping that they will grasp the concepts in a more familiar language. Although I am not certain they understand [them more fully] than when I use Swahili. I normally believe that if I use Swahili at a certain point they will be able to understand better than if I persist with using English ...

Excerpt (10) illustrates that the lecturer uses Swahili to facilitate understanding in a language more accessible to the learners than English. The lecturer's concern in this case is that the students do not understand the content and, as such, he feels compelled to overlook the English-only classroom teaching requirement to ensure that teaching and learning take place without the language barrier standing in the way. Indeed, the use of Swahili is aimed at bridging the language barrier. Nevertheless, the lecturer is not absolutely certain that the desired effect has been attained during the lectures; his hope is that a more familiar language has made a difference.
In some cases, I have a tendency of asking, in my class, whether there is anyone who doesn't speak [Ki]Swahili because I know that at some point I will have to switch to Swahili. You know, so as to make things clearer. So, usually I have this tendency of asking whether there is any non-[Ki]Swahili speaker. I have to be strict. I try as much as possible to speak strictly in English. But if they are all Swahili speakers, every now and then I will try, like if I say something and I see, you know, people are looking at you as if you are from another planet, with blank faces, so I will switch to Swahili so that, like when I want to break things down, to give more explanations, clarifications. Then you have to use Swahili.

In excerpt (11), the lecturer claims that he code-switches to clarify concepts only when there are no non-Swahili speakers in the class. In other words, code-switching is a deliberate teaching practice of a lecturer who understands his or her audience, their limitations, and the situation the students find themselves in, where learning is supposed to take place in an unfamiliar language (English), when the students have a more familiar and accessible language (Swahili) at their disposal.

Generally, these findings reflect Zabrodskaja's (2007) observation that bilingual teachers use two languages to teach academic content. They switch between languages spontaneously or intentionally. They may also decide when to code-switch to facilitate comprehension and meaningful interaction (Zabrodskaja 2007:124). In fact, the lecturers also code-switch between English and Swahili to perform a myriad of social functions, such as advising students to work hard and contribute to national 
development, encouraging them to persevere in their studies, giving them directives, creating humour, socialising with students, clarifying issues, emphasising, and simplifying expressions. The implication is that the lecturers believe that students can easily be encouraged to pay attention and can comprehend issues better when a familiar language is used rather than one imposed on them as a matter of official language policy without taking into account their actual linguistic needs and limitations.

\section{Conclusion}

This paper has illustrated how difficult it is to avoid code-switching in classroom interaction at the tertiary level of education in a multilingual society such as Tanzania. Part of the reason is the problematic language-in-education policy that fails to adequately prepare students for rigorous higherlevel learning in English in a traditionally non-English context where another language dominates. Lecturers of the University of Dar es Salaam, even after having been cautioned against code-switching in classrooms, still persist with code-switching and make it an integral part of their teaching process; primarily to foster learning and bridge the linguistic gap between themselves and their students. Indeed, the findings reveal that lecturers code-switch to facilitate students' comprehension of lesson content. In this regard, they use two types of code-switching, inter-sentential and intra-sentential. They code-switch to fulfil functions such as fostering cohesion, topic development, exemplification, translation of concepts and classroom management. In this regard, code-switching as a sociolinguistic practice is crucial in explaining how a language's peculiar settings and history can facilitate an understanding of the actual linguistic behaviour of its users.

The findings presented in this paper also indicate that lecturers draw on their own bilingualism to relate to a language with which the students are familiar in a bid to facilitate classroom communication and interaction through code-switching. Essentially, this study demonstrates how inseparable speakers are from their linguistic and cultural roots. The code-switching instances presented in this study depict a picture typical of every other bilingual educational context. The use of Swahili by lecturers at the University of Dar es Salaam, despite an official policy banning such use, indicates two important issues. One is not only how difficult it is to sanction an individual from resorting to a familiar language in cases where he or she deems it necessary, but also how pervasive code-switching can be in a bilingual or multilingual situation where the most accessible majority language is not necessarily the official language of instruction.

Moreover, the lecturers' motivations for code-switching largely relate to the use of English as a lingua franca in higher education. Studies on how lecturers and students use English as a lingua franca indicate that they make careful choices and use linguistic and non-linguistic forms to facilitate communication. As Björkman (2011:960) remarks, English in a lingua franca setting is complex not only for students but also for lecturers. This scenario prompts lecturers to invest heavily in different strategies to facilitate classroom communication. Additionally, literature on the use of English as a lingua franca indicates that lecturers in such settings pay attention to deploying several strategies to mitigate communication breakdown. These strategies include codeswitching (cf. Shartiely 2013; Taha 2008). After all, code-switching is characteristic of speakers in bilingual situations. Literature on bilingual speakers indicates that bilinguals access certain advantages that monolinguals do not. For example bilingual teachers can use two languages interchangeably to teach the same content (cf. Zabrodskaja 2007:127). 
On the whole, these findings suggest that code-switching, if taken as a strategy and not a deficiency, can contribute to effective teaching and learning in multilingual societies such as Tanzania. On the basis of the study's findings, this paper recommends an investigation into the existing practices of code-switching to uncover the positive contribution that they make to the development of new knowledge. An additional recommendation is that teaching and LoI policies perhaps be adjusted to provide for the beneficial uses of code-switching and bilingual education. Indeed, such measures can be taken without undermining the value of also developing knowledge through the medium of an international lingua franca such as English, in a manner that allows wider access to information and other social contexts than would otherwise be possible. In this regard, Li (2008:1) suggests that in multilingual situations empirical studies should be done to examine the circumstances under which classroom code-switching is necessary, to identify pedagogically sound and productive codeswitching practices, and to disseminate good code-switching practices through demonstrations, workshops, and teacher-training. More significantly, Lin (2013:212-213) suggests some changes to be made in the type of research done on classroom code-switching in order to gain new insights into this practice. These suggestions include the need for longitudinal research in which the investigator focuses on the same classroom for longer periods instead of just conducting a one-shot videorecording; the need for interventionist research designs that combine interpretive research with action research to enable the teacher to become aware of useful classroom strategies; and the need for a practice of viewing the whole lesson as a genre and investigating the role of the native language in different stages of the curriculum, instead of just looking at instances of code-switching in isolation. Also identified were the need for drawing up specific objectives and designing specific bilingual strategies to achieve those objectives; the need for drawing on the research method of genre analysis to investigate discipline-specific academic discourses and literacies; and the need for integrating research on classroom code-switching with that on multimodality by investigating how classroom participants engage in classroom code-switching and style-switching.

The paper entails a number of policy implications for both the University of Dar es Salaam and policy-makers in general. Specifically, it indicates how lecturers draw on their bilingual status to enrich lectures. The study indicates that all eight lecturers use code-switching, and that their use of this practice is not accidental. They code-switch when they repeat concepts and when they ask questions. They also code-switch for specific purposes of translating or explaining concepts, managing classroom behaviours, and showing solidarity with students. Furthermore, the paper also shows that lectures use codeswitching in the exercise of their agency and voice. Blommaert (2008:428) states that institutions have a tendency to "freeze the conditions for voice". Despite the institutional restrictions, the participants in this study use code-switching as a resource to make themselves understood by others, i.e. to construct voice.

It has become clear that there is a need for continued investigation of how non-native speakers of English of varying levels of proficiency are able to arrive at an understanding of academic work in this medium. Practices such as code-switching project lecturers as change agents who adapt language policy to suit their circumstances (cf. Mashiyi 2014:6). These findings help reveal how participants in their practical contexts do things the way they do, even when this runs contrary to how the things are planned, evaluated and accounted for elsewhere in theory or at a higher hierarchical level in an organisation (cf. Heap 1990). Therefore, this paper recommends that, just as the Tanzanian government has endorsed a policy that allows teachers to use Swahili in teaching in secondary school, it should also consider making the same decision for higher education. Doing so could help avoid the problem of making students struggle with English as they join universities. Such a step would also iron out the ambiguity in the country's language-in-education policy. 


\section{References}

Banda, F. 2007. Study groups and peer roles in mediated academic literacy events in multilingual educational contexts in South Africa. Stellenbosch Papers in Linguistics 37: 1-21.

Bialystok, E. 2001. Bilingualism in development: Language, literacy and cognition. New York: Cambridge University Press.

Bialystok, E. 2009. Bilingualism: The good, the bad, and the indifferent. Bilingualism: Language and Cognition 12(1): 3-11.

Bialystok, E. 2011. Reshaping the mind: The benefits of bilingualism. Canadian Journal of Experimental Psychology/Revue canadienne de psychologie expérimentale 65(4): 229-235.

Bialystok, E., F.I.M. Craik, D.W. Green and T.H. Gollan. 2009. Bilingual minds. Psychological Science in the Public Interest 10(3):89-129.

Björkman, B. 2011. Pragmatic strategies in English as an academic lingua franca: Ways of achieving communicative effectiveness. Journal of Pragmatics 43(4): 950-964.

Blackledge, A. and A. Creese. 2014. Heteroglossia as practice and pedagogy. Springer Netherlands. pp.1-20.

Blommaert, J. 2008. Bernstein and poetics revisited: Voice, globalization and education. Discourse \& Society 19(4): 425-451.

Canagarajah, A. S. 2013. Translingual practice: Global Englishes and cosmopolitan relations. New York: Routledge.

Canagarajah, S. 2011a. Codemeshing in academic writing: Identifying teachable strategies of translanguaging. The Modern Language Journal 95(3): 401-417.

Cenoz, J., B. Hufeisen and U. Jessner (eds.) 2003. The multilingual lexicon. Dordrecht: Kluwer Academic.

Cook, V. 2003. Portraits of the L2 user: Background to the second language user. Available online: http://privatewww.essex.ac.uk/ vcook/portraitsC1.htm. (Accessed 12 June 2012).

Creese, A. and A. Blackledge. 2010. Translanguaging in the bilingual classroom: A pedagogy for learning and teaching? The Modern Language Journal 94(1): 103-115.

Fishman, J. 1967. Bilingualism with and without diglossia; diglossia with and without bilingualism. Journal of Social Issues 23(2): 29-38.

García, O. 2009. Education-multilingualism-translanguaging-21st-century. In Bilingual education in the 21st century: A global perspective. pp. 141-158.

Grosjean, F. 2008. Studying bilinguals. Oxford: OUP. 
Grosjean, F. 1982. Life with two languages. Cambridge, MA: Cambridge University Press.

Gulzar, M.A. 2010. Code-switching: Awareness about its utility in bilingual classrooms. Bulletin of Education and Research 32(2):23-44.

Gumperz, J.J. 1982. Discourse strategies. Cambridge: Cambridge University Press.

Gumperz, J. and B. Bloom. 2000. Social meaning in linguistic structure: Code-switching in Norway. In W. Li (ed.). The bilingualism reader. London: Routledge. pp. 111-136.

Hamers, J.F. and M.H.A. Blanc. 2000. Bilingual and bilingualism ( $2^{\text {nd }}$ edition). Cambridge: Cambridge University Press.

Heap, J. 1990. Applied ethno methodology: Looking for the local rationality of reading activities. Human Studies 13(1):39-72.

Hibbert, L. and C. van der Walt. 2014. Multilingual universities in South Africa. London: Multilingual Matters.

Kagwesage, A. M. 2013. Coping with English as language of instruction in higher education in Rwanda. International Journal of Higher Education 2(2): 1-12.

Lenis, M. E. L. 2015. Translanguaging and identity in a kindergarten classroom: Validating students' home culture and language in an English-only era. Doctoral dissertation. Massachusetts: University of Massachusetts Amherst.

Li, D. 2008. Cantonese-English code-switching research in Hong Kong: A Y2K review. World Englishes 19(3): 305-322.

Lin, A. M. Y. 2013. Classroom code-switching: Three decades of research. Applied Linguistics Review 4(1): 195-218.

Mashiyi, N. 2014. Towards promoting a responsive and inclusive tertiary education system in South Africa through multilingualism. International Journal of Education Science 6(1): 1-9.

Mwinsheikhe, H.M. 2009. Spare no means: Battling with the English/Swahili dilemma in Tanzanian secondary school classrooms. In B. Brock-Utne and I. Skattum (eds.) Languages and education in Africa: A comparative and transdisciplinary analysis. Providence: Symposium Books.

Myers-Scotton, C. 1993. Common and uncommon ground: Social and structural factors in code switching. Language in Society 22(4): 475-503.

Myers-Scotton, C. 1997. Duelling languages, grammatical structure in code switching (2 $2^{\text {nd }}$ edition). Oxford: Oxford University Press.

Olmo-Castillo, W. N. 2014. Teachers' attitudes towards code switching within a bilingual classroom. MA thesis. Brockport: State University of New York College. 
Poplack, S. 2001. Code switching: Linguistic. In N.J. Smelser and P.B. Baltes (eds.) International Encyclopaedia of the Social and Behavioural Sciences. pp. 2062-2065.

Rubagumya, C.M. 2008. Going through the motions of learning: Classroom interaction in Tanzania. In B. Brock-Utne, Z. Desai and M. Qorro (eds.) LOITASA: Reflecting on Phase I and entering Phase II. pp. 143-159.

Shartiely, N.E. 2013. Discourse Strategies of Lecturers in Higher Education Classroom Interaction: A case at the University of Dar es Salaam, Tanzania. Doctoral dissertation. Stellenbosch: University of Stellenbosch.

Shin, S.J. and L. Milroy. 2000. Conversational code-switching among Korean-English bilingual children. International Journal of Bilingualism 4(3): 351-383.

Shin, S-Y. 2010. The functions of code-switching in a Korean Sunday School. Heritage Language Journal 7(1): 91-116.

Swann, J. and I. Sinka. 2007. Style shifting, code-switching. In D. Graddol, D. Leith, J. Swann and M. Rhys (eds.) Changing English. New York: Routledge

Swilla, I.N. 2009. Languages of instruction in Tanzania: Contradictions between ideology, policy and implementation. African Study Monographs 30(1): 1-14.

Taha, T.A. 2008. Language alternation in university classrooms. Journal of Instructional Psychology 35(4): 336-347.

The Ministry of Education and Vocational Training. 2014. Education and Training Policy. Available online: www.tamisemi.go.tz. (Accessed July 2016).

Uys, D. 2010. The functions of teachers' code-switching in multilingual and multicultural high school classrooms in the Siyanda District of the Northern Cape Province. MPhil thesis. Stellenbosch: Stellenbosch University.

Van der Walt, C. and N. Klapwijk. 2015. Language of learning and teaching in a multilingual school environment: What do teachers think? Language Matters 46(2): 293-318.

Walker, V. 2011. Codeswitching as a power and solidarity strategy in the foreign language classroom. An analysis of language alternation strategies utilised in a Portuguese-English higher education class. Leading Undergraduate Work in English Studies (3): 351-363.

Wei, L. 2005. Starting from the right place: Introduction to the special issue on conversational code-switching. Journal of Pragmatics 37: 275-279.

Wei, L. 2011. Moment analysis and translanguaging space: Discursive construction of identities by multilingual Chinese youth in Britain. Journal of Pragmatics 43: 1222-1235.

Westly, E. 2011. The bilingual advantage. Scientific American Mind 22(3): 38-41. 
Young, V. A., R. Barrett, Y. Young-Riviera and K.B. Lovejoy. 2013. Other people's English: Code-meshing, code-switching, and African American Literacy. New York and London: Teachers College Press, Columbia University.

Zabrodskaja, A. 2007. Russian-Estonian code-switching in the university. SLA \& Teaching (14): 123-139.

Zabrodskaja, A. 2008. Code-switching and L2 students in the university: Bilingualism as an enriching resource. JoLIE (1): 99-114.

Zabrodskaja, R.A. 2009. Russian-Estonian language contacts: Grammatical aspects of language use and change. Doctoral dissertation. Tallinn: Tallinn University. 